\title{
Application of focus-variation Technique in Measurements of Ultrasonic Vibrations of Grinding pins
}

\author{
Roman Wdowik ${ }^{1, a}$ \\ ${ }^{1}$ Rzeszów University of Technology, al. Powstańców Warszawy 12, 35-959 Rzeszów, Poland
}

\begin{abstract}
The paper presents the application of focus-variation technique in measurements of ultrasonic vibrations of grinding pins. Ultrasonic vibrations of tools are applied in ultrasonic assisted grinding. Their measurements are significant for development of this hybrid machining process. Alumina and zirconia ceramic materials in the final fired state were machined in experiments which are known as scratch tests. Diamond grinding pin was used as a tool to machine scratches. Marks of diamond grains, left on the surface of workpieces after machining process, were investigated using The Infinite Focus Real $3 D$ optical microscope. Focus-variation is the principle of operation of this microscope. Investigations concerned possibilities of measurements of an amplitude of axial and radial vibrations in the case of two ceramic materials. Results of performed measurements are presented and discussed for selected machining parameters.
\end{abstract}

\section{Introduction}

There is the great need to investigate the parameters of ultrasonic vibrations of grinding pins which are used in ultrasonic assisted grinding with tool vibration. Grinding pins are a kind of grinding wheels. The abrasive layer is fixed to a metal mandrel and diameters of grinding pins are usually relatively small. Ultrasonic assisted grinding is one of hybrid machining processes. In this process, beside ultrasonic oscillations of a grinding pin, the tool also rotates. Connection of these two motions is used to improve the process course and its results (e.g. process forces may be lowered, self-cleaning effect helps to remove material from wheel's surface). Amplitude and frequency of ultrasonic vibrations are usually indicated as main parameters of oscillatory motion of grinding pins. It has been stated $[1,2,7,8]$ that, depending on construction of grinding tool, both, radial and axial vibrations may be detected. The results of measurements of parameters of vibrations are significant in modeling and optimization of ultrasonic assisted grinding. They also help to understand the process course.

There are many methods and specific devices which can be applied in measurements of ultrasonic vibrations. Laser doppler vibrometers, eddy current sensors and microscopes are, inter alia, used for this purpose. The contractors of project and raport [1] tested these methods and proved their usability. Wdowik et al. [2] investigated in details eddy current sensors and compared the results of measurements with these after measurements with the use of laser doppler vibrometers. He also did in-process measurements of axial ultrasonic vibrations using laser doppler vibrometer and did not observe amplitude

\footnotetext{
${ }^{\mathrm{a}}$ Corresponding author: rwdowik@prz.edu.pl
}

damping [3]. Many authors state that optical microscopes are useful in measurements of ultrasonic parameters. Cong et al. [4] observed the surface of workpieces after machining and measured marks left by grains of diamond drilling tool. They drilled holes in ultrasonic assisted grinding with tool vibrations and measured ultrasonic parameters on rods' surface. Lauwers et al. [5] and Uhlmann et al. [6] observed marks on the surface of the machined workpiece. Vanparys [7] observed vibrations using microscope under five hundredfold magnification.

The previous investigations were mainly concentrated on microscopic measurements of axial vibrations but the possibilities of these measurements still have not been described in details. There is also no information in the literature, available for the author of this article, about measurements of radial ultrasonic vibrations with the use of optical microscopes.

\section{Experimental setup}

Investigations were performed using two ceramic materials $-\mathrm{Al}_{2} \mathrm{O}_{3}$ and $\mathrm{ZrO}_{2}$ based ceramics. CNC hybrid machine tool Ultrasonic 20 linear was applied for these investigations. It is the machine tool which allow to realize ultrasonic assisted grinding process with vibrations of a tool $u$. Ten scratches were performed on the one side of ceramic workpiece (refer with: Fig. 1). The surface of every scratch was concave because of the shape of the grinding pin. Different machining parameters were set for each scratch (refer with: Fig. 1 and Table 1). Then, scratches were investigated on The Infinite Focus Real 3D microscope from Alicona 
company. The traces of diamond grains, left on the surface of the workpiece, were mainly investigated. Their shape is similar to the shape of a sine function because a tool rotates and vibrates at the same time (refer with: Fig. 1). The measurements on the selected microscope are based on focus-variation technique. This technique is an area based technique for 3D surface measurements in the highest vertical resolution and it is described in the most recent EN ISO standard 25178 [9].
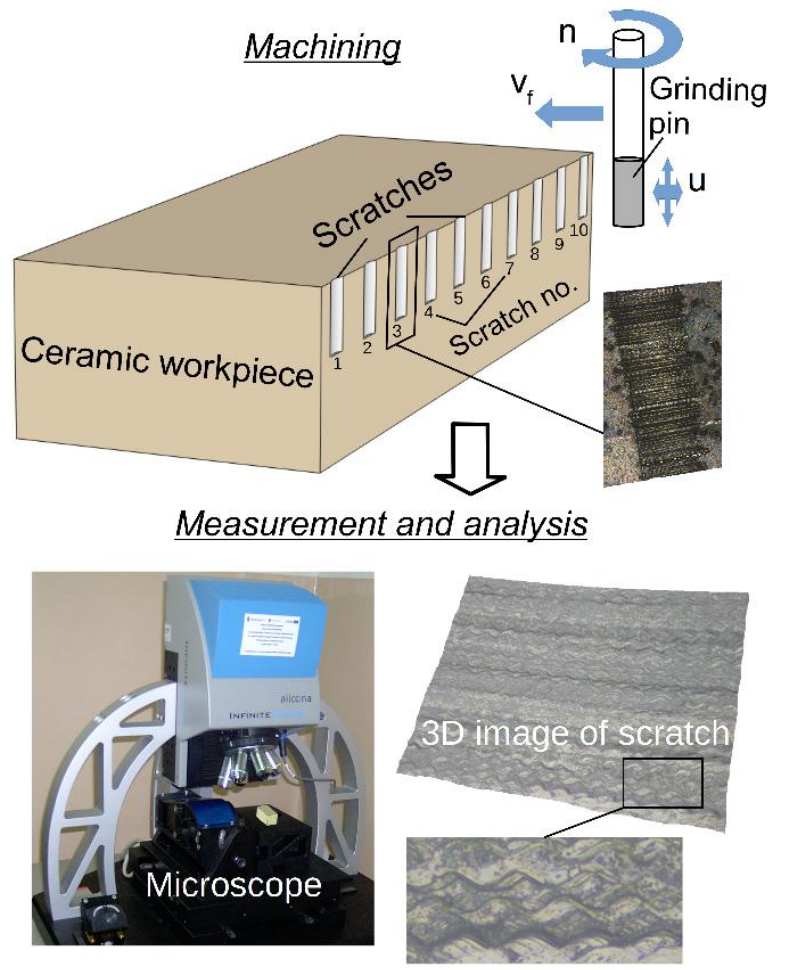

Figure 1. Strategy of scratching of ceramic workpieces on the hybrid Ultrasonic 20 linear machine tool and The Infinite Focus Real 3D microscope used for 3D focus-variation measurements

During previous investigations [2,3] the best results of measurements were achieved if laser doppler vibrometer was applied. Measurements proved that both, radial and axial vibrations of grinding pins, may be detected with the use of laser doppler vibrometer. It was interesting for the author to check whether radial and axial vibrations will be detected during microscopic investigations. The preliminary investigations were performed [10] but their results have not convinced the author whether radial vibrations may be measured on microscopes. The Infinite Focus Real 3D microscope allows to scan a surface of an object and 3D model of the surface is generated. The microscope's software let analyze 3D models. At the beginning, it was necessery to find the proper software's tools for scheduled measurements. The visibility of axial vibrations on 2D and 3D microscopic images is generally sufficient but the right machining parameters have to be set. Visibility also depends on material properties. It is better for zirconia then in the case of alumina ceramic material. Figure 2 presents the examples of preselected tools of the software of The Infinite Focus Real 3D microscope. The possible software's tool for radial ultrasonic vibrations is cutting plane tool (refer with: Fig. 2a) or the tool for surface topography inspection (refer with: Fig. 2b). It was assumed that a cutting plane tool should allow to create the profile of intersection of 3D model and cutting plane in order to define the distance between possitions of diamond grain during machining process. It is a distance between the top and the bottom of created profile. This distance is measured in radial direction (parallel to a radius of a grinding pin). Similar observations are possible if the tool for inspection of a surface topography is applied (refer with: Fig. 2b). The colours of a model indicate the height and allow to define the difference between grain positions during machining process in radial direction. The red dots in Fig. $2 \mathrm{~b}$ may indicate the radial ultrasonic vibrations.

Axial vibrations are clearly visible on $2 \mathrm{D}$ or $3 \mathrm{D}$ models of the workpiece's surface. The measurements are possible using 2D models and the tools for distance measurements (refer with: Fig. 2c). The microscopic measurements of axial vibrations are described in details in work [3]. After preselection of tools of the software it was possible to perform the measurements and to present their results.

Table 1. Experimental data

\begin{tabular}{|c|c|c|c|c|c|c|c|c|c|c|}
\hline $\begin{array}{l}\mathrm{Al}_{2} \mathrm{O}_{3} \text { based } \\
\text { ceramic } \\
\text { material }\end{array}$ & \multicolumn{10}{|c|}{$\begin{array}{l}\text { Material properties: } \\
\text { hardness: } 12.09 \pm 0.13[\mathrm{GPa}] \text {, } \\
\text { porosity: } 0.01[\%], \\
\text { density: } 3.92\left[\mathrm{~g} / \mathrm{cm}^{3}\right] .\end{array}$} \\
\hline $\begin{array}{l}\mathrm{ZrO}_{2} \text { based } \\
\text { ceramic } \\
\text { material }\end{array}$ & \multicolumn{10}{|c|}{$\begin{array}{l}\text { Material properties: } \\
\text { hardness: } 12.78 \pm 0.1[\mathrm{GPa}] \text {, } \\
\text { porosity: } 0.01[\%] \\
\text { density: } 6.07\left[\mathrm{~g} / \mathrm{cm}^{3}\right] .\end{array}$} \\
\hline Scra & 1 & 2 & 3 & 4 & 5 & 6 & 7 & 8 & 9 & 10 \\
\hline $\begin{array}{l}\text { Rotational } \\
\text { speed } \\
\mathrm{n},\left[\mathrm{min}^{-1}\right]\end{array}$ & $\stackrel{8}{\varrho}$ & 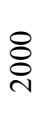 & ¿্ঠ & ஓ̊ & 官 & 8 & \& & 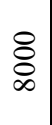 & \& & 8 \\
\hline $\begin{array}{l}\text { Other } \\
\text { parameters } \\
\text { and grinding } \\
\text { pin }\end{array}$ & \multicolumn{10}{|c|}{$\begin{array}{l}\mathrm{v}_{\mathrm{f}}=20[\mathrm{~mm} / \mathrm{min}] \text { (feed, } 1 \mathrm{~s} \text { pause was } \\
\text { applied after touching the surface), } \\
\mathrm{f}_{\mathrm{USg}}=25100 \text { [Hz] (frequency of } \\
\text { ultrasonic oscillations), } \\
\text { diamond grinding pin: } \Phi 8 \mathrm{D} 91 \mathrm{H} \text { from } \\
\text { Schott company. }\end{array}$} \\
\hline Machine tool & \multicolumn{10}{|c|}{$\begin{array}{l}\text { Ultrasonic } 20 \text { linear from Sauer (DMG) } \\
\text { company }\end{array}$} \\
\hline Microscope & \multicolumn{10}{|c|}{$\begin{array}{l}\text { The Infinite Focus Real } 3 D \text { microscope } \\
\text { from Alicona company }\end{array}$} \\
\hline
\end{tabular}

\section{Results of experiments}

It is easy to detect the traces of grains which are similar to the shape of sine function in the case of $\mathrm{ZrO}_{2}$ based ceramic material (refer with: Fig. 3). These traces are also visible in the case of alumina ceramic but it is not as easy as in the case of zirconia to detect them (refer with: Fig. 4). The mechanism of material removal is based on brittle fracture during machining of $\mathrm{Al}_{2} \mathrm{O}_{3}$ based ceramic material while machining of $\mathrm{ZrO}_{2}$ based ceramic material reveals ductile material removal mechanism. The traces have different shapes for different spindle speeds. If the spindle speed decreases, the shorter distances between 
single tops and bottoms of the grains' traces are detected. If the speed is too high it is difficult to detect the traces which are similar to the sine function. It is shown in Fig. 3 in the case of the spindle speed $\mathrm{n}=9000 \mathrm{~min}^{-1}$. Amplitude of axial ultrasonic vibrations may be defined on $2 \mathrm{D}$ images as the half of the distance between tops and bottoms of the trace (refer with: Fig. 2c).

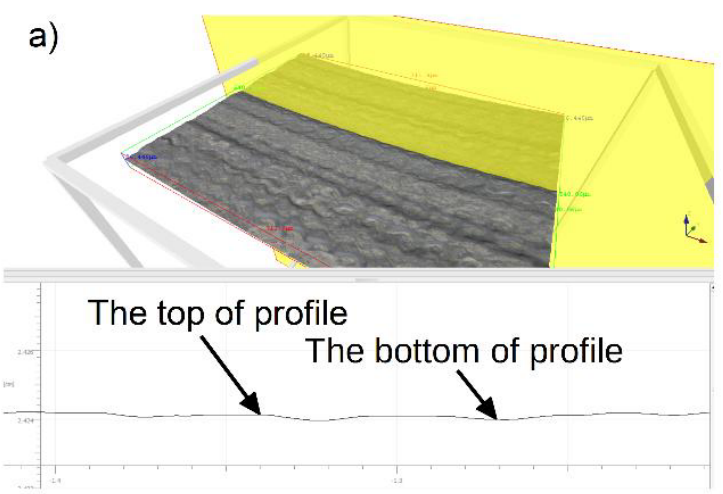

b)

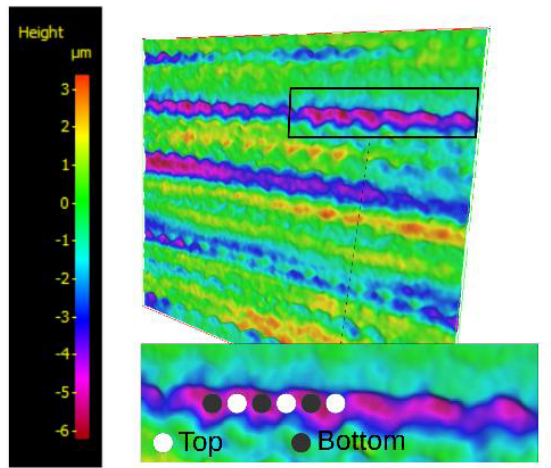

c)

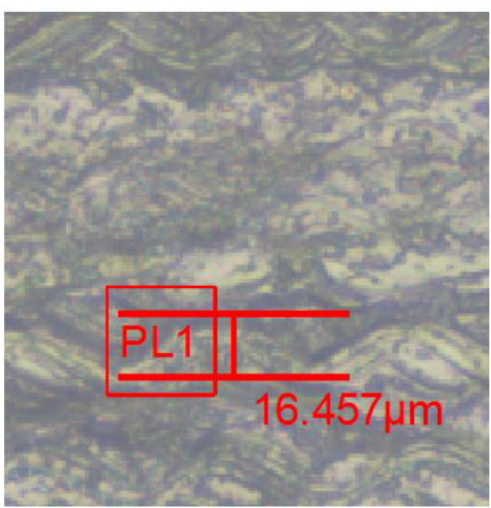

Figure 2. The tools of software of Infinite Focus Real 3D microscope used for 3D measurements of parameters of ultrasonic vibrations on ceramic workpieces: a) cutting plane and profile analysis, b) surface topography, c) 2D measurements

It can be stated, for all selected values of a spindle speed and other machining conditions, that the maximum value of spindle speed for the measurements of vibrations should be set up to $\mathrm{n}=6000 \mathrm{~min}^{-1}$. Then, amplitude can be easily measured.
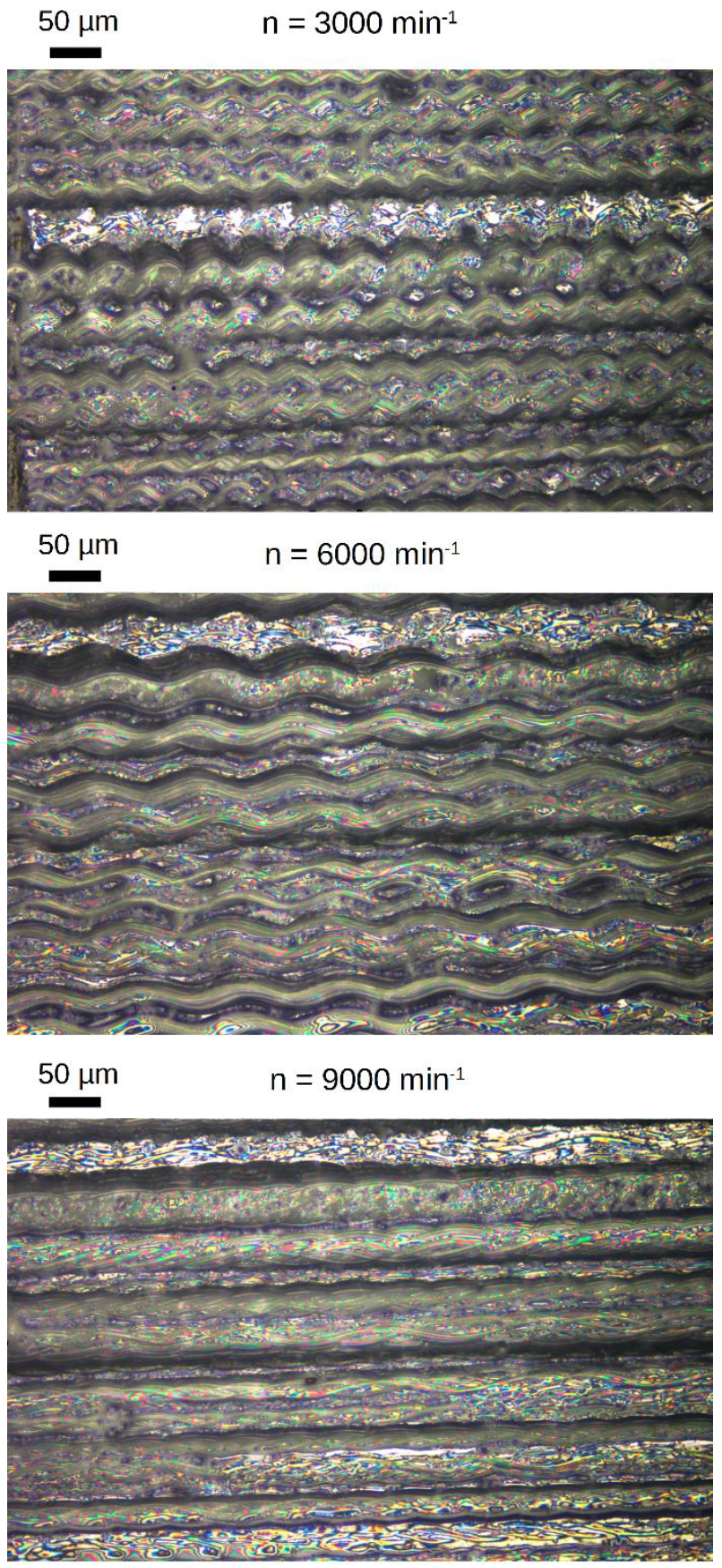

Figure3. Example of the change of the shape of grains' traces in the case of $\mathrm{ZrO}_{2}$ based ceramic

Measurements of radial vibrations are much more difficult in the case of performed microscopic investigations. It was difficult to detect radial vibrations using cutting plane tool presented in Fig 2a. The intersection profiles had the shape of sine waves but it was the result of grain traces and axial ultrasonic vibrations. Using the cutting plane tool in the case of very small fragments of 3D surface also did not give the good results of measurements. It can be stated that this software's tool is not useful during measurements. Therefore, there was applied the second tool of the software for inspection of surface topography that is presented in Fig. 2b. The scratch's surface and also the 
3D model of surface are concave because of the grinding pin shape, so it was necessary to use form removal tool of the software to analyze the vibrations (refer with: Fig. 5). It was usually not possible to observe differences in positions of grains in radial direction and most of the images generated after scanning process were similar to the image in Fig. 5b. The possible evidence of the existence of radial ultrasonic vibrations is presented in Fig. 2c for $\mathrm{ZrO}_{2}$ based ceramic material because the red areas lay lower than blue and pink areas.

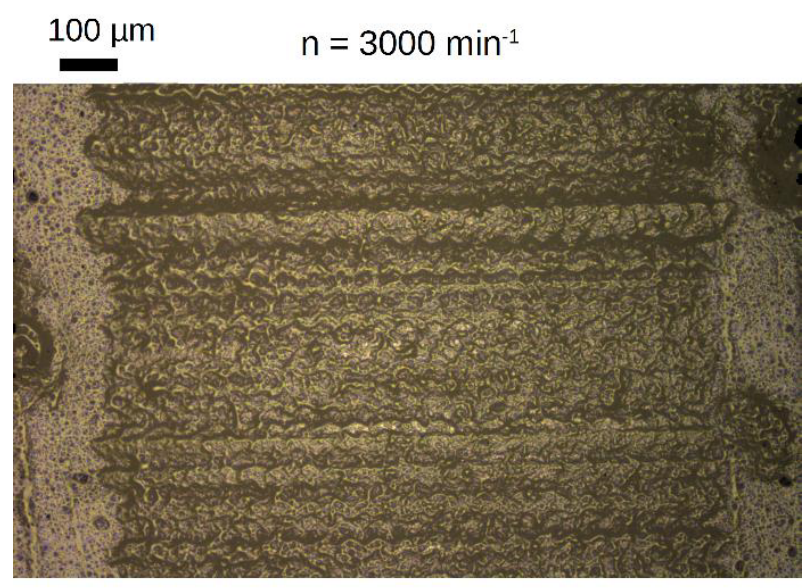

$$
100 \mu \mathrm{m} \quad \mathrm{n}=6000 \mathrm{~min}^{-1}
$$
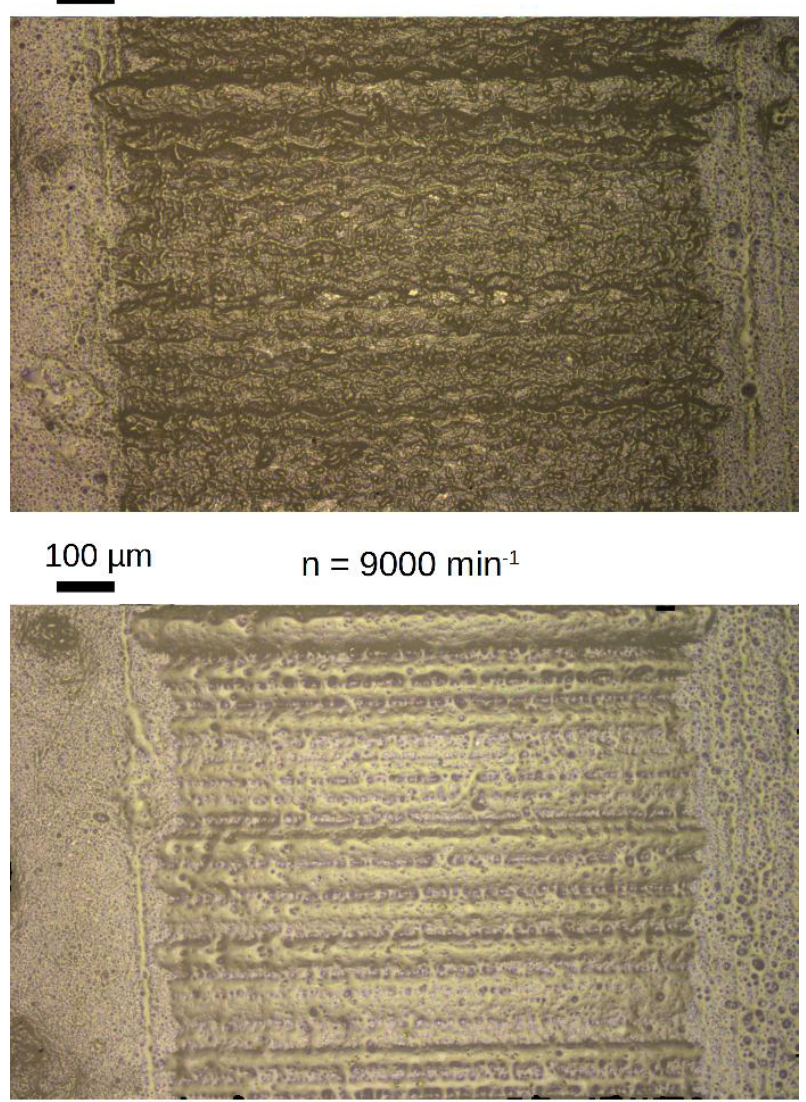

Figure 4. Example of the change of the shape of grains' traces in the case of $\mathrm{Al}_{2} \mathrm{O}_{3}$ based ceramic

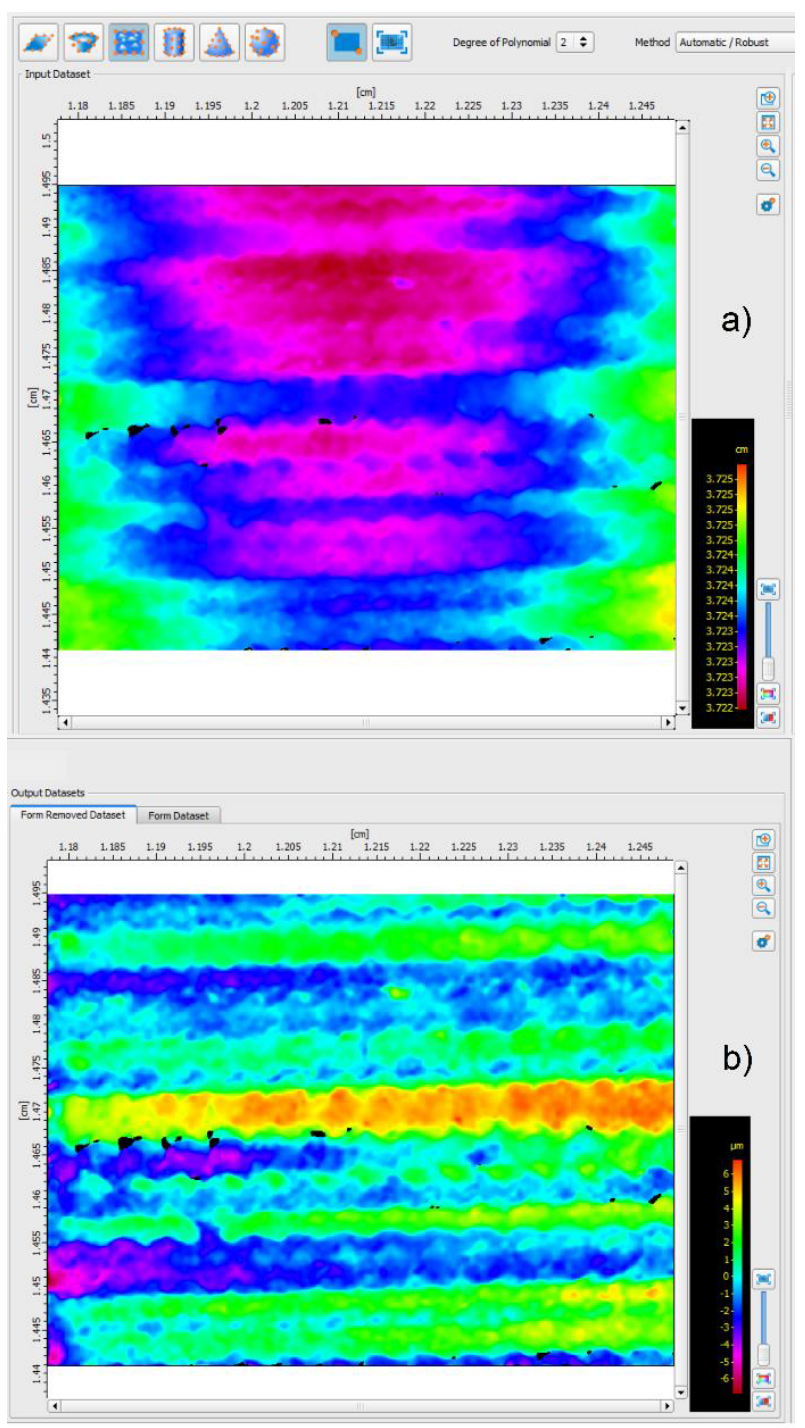

Figure 5. Example of measurement of radial ultrasonic vibrations: a) input 3D model, b) model after removing the concavity using polynomial (degree of polynomial equals 2 )

\section{Summary}

It can be stated that measurements of axial ultrasonic vibrations are possible using microscopic images for $\mathrm{Al}_{2} \mathrm{O}_{3}$ and $\mathrm{ZrO}_{2}$ based ceramic material but the maximum spindle speed for these measurements, in selected machining conditions, should be up to $6000 \mathrm{~min}^{-1}$. The visibility of vibrations is better for $\mathrm{ZrO}_{2}$ based ceramic material because of ductile material removal mechanism. The previous investigations are therefore confirmed.

It is difficult to state that microscopic measurements of radial vibrations are possible because most of the results indicated no differences in the positions of diamond grain in radial direction. It is also possible that, because of the contact of a grinding pin with the surface, radial vibrations are damped. The detailed investigations will be performed in the future for selected machining parameters and other materials. Pre-sintered (softer) ceramic materials will be also investigated (similar to the investigations which are presented in work [11]). 


\section{Acknowledgement}

The research work was the part of the statutory activity of young researchers at Rzeszów University of Technology (U-562/DS/M). Author would like to thank Jacek Misiura, MSc from The Department of Manufacturing Techniques and Automation for his help during operating the microscope and Cerel company in Boguchwała for ceramic samples and defining their properties.

\section{References}

1. Ultrasonic Assisted Grinding of brittle hard materials. Final Technical report - April $28^{\text {th }} 2010$, Cornet project, 1-75.

2. R. Wdowik, P. Nazarko, J. Porzycki: Application of LDV device and eddy current sensor system for ultrasonic vibrations measurements. [in: Advances in Intelligent Systems and Computing, Volume: Mechatronics - Ideas for Industrial Application], Springer International Publishing, Vol. 317, 2015, 407-415, doi:10.1007/978-3-319-10990-9 38.

3. R. Wdowik: Analysis of ultrasonic assisted grinding of alumina and zirconia ceramics (in Polish), Doctoral dissertation, Rzeszów University of Technology, 2015.

4. W. L. Cong, Z. J. Pei, N. Mohanty, E. Van Vleet, C. Treadwell: Vibration Amplitude in Rotary Ultrasonic Machining: A Novel Measurement Method and Effects of Process Variables. Journal of Manufacturing Science and Engineering 133, 2011, p. 034501-1-034501-5.
5. B. Lauwers, F. Bleicher, P. Ten Haaf, M. Vanparys, J. Bernreiter, T. Jacobs, J. Loenders: Investigation of the Process - Material Interaction in Ultrasonic Assisted Grinding of $\mathrm{ZrO} 2$ based Ceramic Materials. Proceedings of the $4^{\text {th }}$ CIRP International Conference on High Performance Cutting, 2010.

6. I. D. Marinescu, M. Hitchiner, E. Uhlmann, W. B. Rowe, I. Inasaki: Handbook of Machining with Grinding Wheels. CRC Press, Taylor and Francis Group, 2007, 549-562.

7. M. Vanparys: Ultrasonic assisted grinding of ceramic components. Doctoral dissertation, KU Leuven, 2012.

8. C. Brecher, R. Schug, A. Weber, C. Wenzel, S. Hannig: New systematic and time-saving procedure to design cup grinding wheels for the application of ultrasonic-assisted grinding. Int. J. Adv. Manuf. Technol., 47, 2010, 153-159, doi: 10.1007/s00170009-2204-7.

9. http://www.alicona.com (webpage checked 09/10/2015).

10. R. Wdowik, J. Porzycki, J. Świder, P. Nazarko: Microscopic estimation of axial ultrasonic oscillations parameters (in Polish). Mechanik 8(9), 2013, 417-423.

11. M. Magdziak, R. Wdowik: Coordinate Measurements of Geometrically Complex Ceramic Parts. Applied Mechanics and Materials, Trans Tech Publications, Switzerland, Vol. 627, 2014, 172-176, doi:10.4028/www.scientific.net/AMM.627.172. 